\title{
NOVEL CONSTITUTIVE MODELLING APPROACH FOR SHAPE MEMORY ALLOYS VIBRATION CONTROL DEVICES
}

\author{
KACPER WASILEWSKI $^{1 *}$ AND ARTUR ZBICIAK ${ }^{2}$ \\ ${ }^{1}$ Faculty of Civil Engineering \\ Warsaw University of Technology \\ 16 Armii Ludowej Ave., 00-637 Warsaw, Poland \\ e-mail: k.wasilewski@il.pw.edu.pl, http://www.il.pw.edu.pl (*corresponding author) \\ ${ }^{2}$ Faculty of Civil Engineering \\ Warsaw University of Technology \\ 16 Armii Ludowej Ave., 00-637 Warsaw, Poland \\ e-mail: a.zbiciak@il.pw.edu.pl,http://www.il.pw.edu.pl
}

Keywords: Shape Memory Alloys, Rheological model, Seismic engineering, Non-linear vibrations

\begin{abstract}
One of the main fields of shape memory alloy application in civil engineering is oriented on mitigation of earthquake effects on structures. Vibration isolators that incorporate elements made of SMA take advantage of its characteristic phenomenon of nonlinear hysteretic response, also known as superelasticity. In this work, authors presents an approach to phenomenological modelling of SMA by using rheological schemes. One of the advantages of this approach is a possibility of formulation of constitutive relationships as a set of explicit differential equations. As an illustration of validity of the formulation, authors present the response of single degree of freedom oscillator that incorporates SMA elements modelled by different existing SMA models. The response obtained based on the model that uses rheological schemes is compared with Lagoudas thermodynamic constitutive SMA model and simplified material model. All of the compered models are found to match well and show important reduction in displacement transmissibility.
\end{abstract}

\section{INTRODUCTION}

Shape memory alloys (SMA) belongs to the family of smart materials being comprehensively studied in recent decades. One of the main fields of its application in civil engineering is oriented on mitigation of earthquake effects on structures. Vibration control devices that incorporate elements made of SMA take advantage of its characteristic phenomenon of nonlinear hysteretic response, also known as superelasticity [1]. Such devices are especially promising for retrofitting and protection of architectural heritage what was verified in several application for strengthening of cultural heritage structures.

In this work, authors present a novel approach to modelling of SMA by using rheological schemes. As an illustration of validity of the formulation, authors present the response of a single degree of freedom oscillator that incorporates SMA elements modeled by different existing SMA models. The response obtained based on the model that uses rheological schemes 
is compared with thermodynamic constitutive SMA model developed by Lagoudas et al. [2, 3] and simplified material model also presented by Lagoudas et al. [4].

\section{CHARACTERISTICS OF SMA}

The first observations of shape memory specific characteristic behaviour were done during the first half of $20^{\text {th }}$ century. First in 1932, Ölander observed "rubber like effect", later named as superelasticity, in an alloy of gold and cadmium [5]. Further studies of this alloy led to observation of "shape recovery", later named as shape memory effect, by Chang and Read in 1951 [6]. The breakthrough event for SMA studies was the discovery of Nitinol, an alloy of nickel and titanium, in 1963 by Buehler and co-workers from U.S. Naval Ordnance Laboratory [7]. Since then it has been discovered that alloys such as copper-zinc-aluminium alloy [8], copper-aluminium-nickel alloy, iron-platinum alloy, iron-palladium or iron-manganese-silicon alloy [9] presents similar unique properties. However, the Nitinol is considered as the alloy that shows the best shape memory properties [10]. SMAs find applications in various fields of engineering such as aeronautics [11], biomedical engineering [12] (especially cardiovascular applications [13]) and structural engineering [14, 15].

The main characteristic of SMAs that benefits for the application in the structural engineering field is superelasticity. This phenomenon can be described based on the graph of the response for the uniaxial tension test of the SMA specimen (Figure 1). After the initial, close to linear, response the superelastic plateau occurs. This kind of response is similar to the

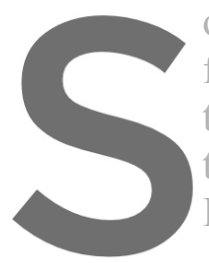
one observed during yieic from austenite to marters the further elastic trans the reverse phase transf It results in almost complete strain recovery.
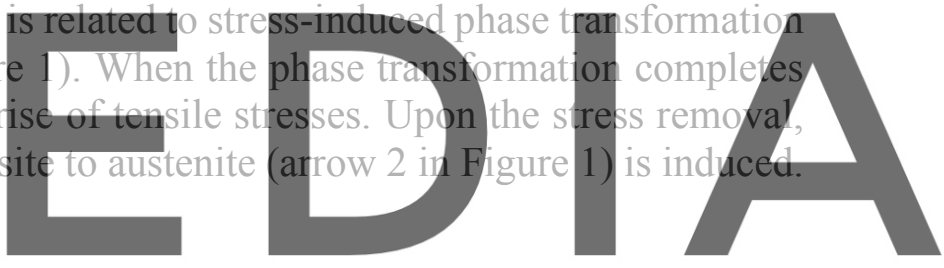

Register for free at https//wäw.scipedia.com to download the version without the watermark

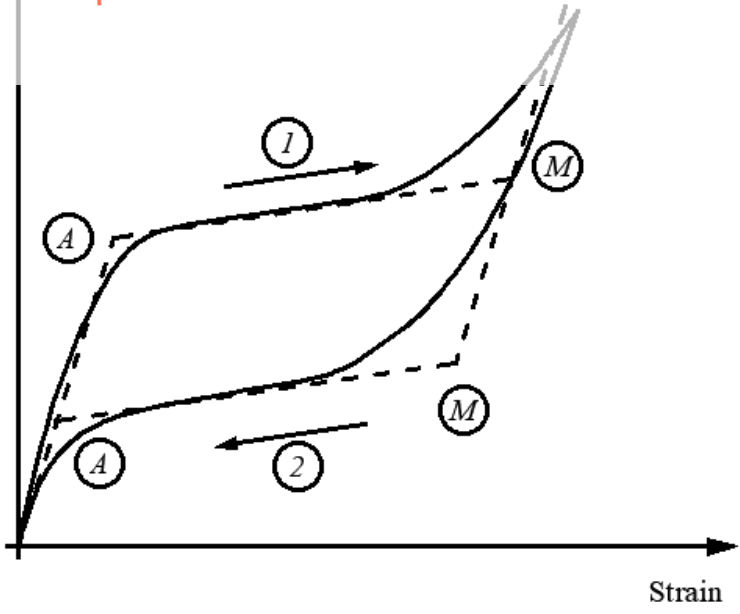

Experimental

- - - Num erical simplification

Figure 1: Shape of hysteresis loop of SMA and its numerical simplification 


\section{SMA IN RETROFITTING OF HISTORICAL STRUCTURES}

Applications of SMA in strengthening of cultural heritage structures base on the traditional tying techniques increasing the box-type behaviour of the building. The performance of ties that incorporate SMA elements is enhanced due to the phenomenon of the superelasticity. In case of ground motions with low intensity or other horizontal loads the SMA elements work in the first, elastic branch (Figure 1) what results in behaviour similar to classic (e.g., steel) ties. In case of strong ground motion, SMA elements undergo phase transformation what effects in reduction of stiffness and allowance for controlled displacement of tied members. This phenomenon permits the structure to dissipate part of the energy through a microcracking instead of a dangerous macrocracking. The displacement is later recovered upon the load removal. The noticeable fact is a lower force transmitted to the historical material. Finally, in case of severe ground motion or other extraordinary horizontal load the stiffness of SMA elements increase what helps preventing from excessive displacements [16].

The reinforcement technique for historical structures that incorporates SMA was studied and developed within the ISTECH Project [17]. It based on a device, equipped with wires made of SMA, that reduce the risk of collapse of masonry buildings in case of strong earthquake actions. The trial intervention was implemented in 1999 during restoration of bell tower of San Giorgio church in Trignano after the earthquake in October 1996 which struck the Reggio Emilia and Modena Districts (Italy) [18]. SMA devices were installed as a parts of vertical post-tensioned

\section{ties that improve bending and shear resistance (Figure 2a). Despite the numerical and} experimental campaig after which the structure s. a technique.
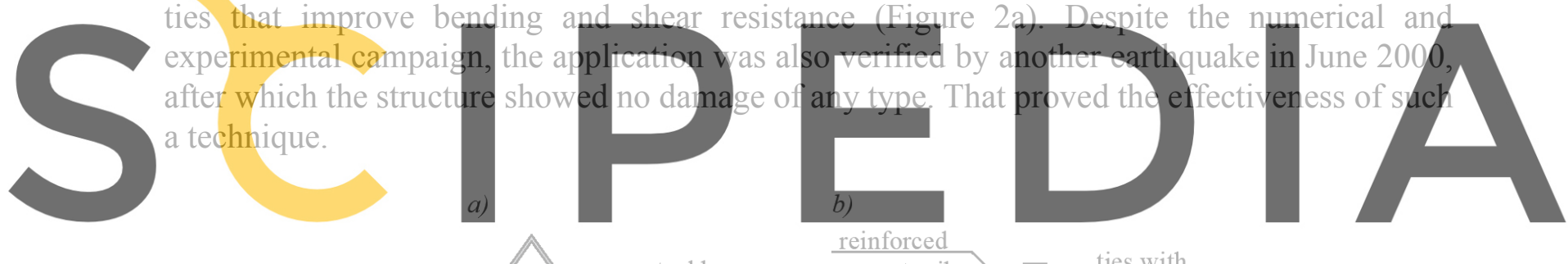

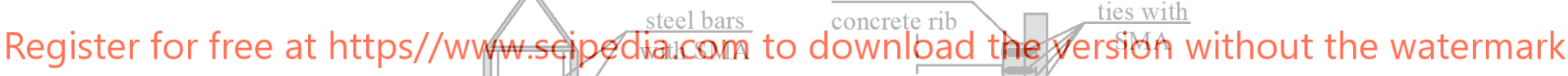
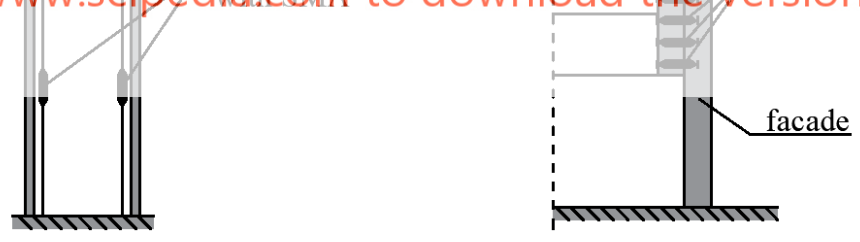

Figure 2: Schemes of the SMA devise arrangements for retrofitting of historical structures - (a) vertical ties in slender structures [18] and (b) horizontal ties for facades [16]

The successful results of the research and exploitation of ISTECH project led to the further application of SMA in restoration of the Basilic of San Francisco in Assisi and the Cathedral of San Feliciano in Foligno [16]. In those cases the strengthening was intended to improve the connection between perpendicular elements (Figure 2b), such as the transept tympanum (in the Basilic of San Francisco) and the façade (in the Cathedral of San Feliciano). Such an intervention aim at the prevention of a out-of-plane collapse of tied elements.

Another investigation was performed by Cardone et al. [19] who examined a behavior of SMA implemented in ties of timber roof trusses. The experimental campaign, that included 
thermal behavior and shaking table tests, led to the installation of prototype device in the San Paolo Eremita church in Brindisi.

Presented applications of SMA in historical structures show their several advantages. The improvement of box-type behaviour of buildings, originated from traditional ties, is followed by possibility of controlled displacement that leads to energy dissipation. Moreover, the features of SMA, allow to control the forces in ties not only related to the seismic event but also to changes of temperature, corrosion, and relaxation due to deformation of masonry (creep) [18-20].

\section{NUMERICAL MODELLING OF SMA}

According to Cisse et al. [21] the constitutive models of SMA could be divided in terms of modelling scale and mathematical structure in the following groups:

- microscopic thermodynamic models,

- micro-macro models and

- macroscopic models.

The models from the first category describe microstructural features in SMA behaviour (e.g., phase nucleation, interface motion, martensite twin growth) at the lattice or grain-crystal levels. The models from the following category rely on micromechanics to describe the material behaviour at the micro or meso scales and then based on a scale transition macroscopic constitutive equations are derived. The last group consists of the models that describe the

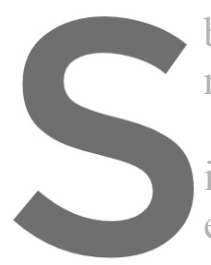
behaviour of polycrystalline SMAs based on
micro-macro thermodynamics or direct experime
In case of the analysis of the applications in th
is to study the influence of SMA elements incor
excitation. In such a case the most efficient mode phenomenological considerations,
nental data fitting $[21]$.
the field pf structural engineering th
orporated in the structure to its resp
dels are the phenomenological macro

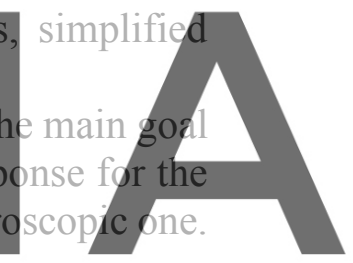

4.1 SMA vilbration control devices modelling with rheological schemes

Register for free at https//www.scipedia.com to download the version without the watermark The concept of modelling SMA as a certain set of rheological elements was earlier discussed by authors in [22-26]. This approach belongs to the group of macroscopic models of SMA and allows to analyse behaviour of structural members without a detailed analysis of the phenomena at the microcrystal level.

The model of a vibration control device can be represented as a single degree of freedom system (Figure 3a) where the mass displacement is given by $X(t)$ and base displacement by $Y(t)$. In this configuration the SMA element is given as a "black box" that expresses the particular set of rheological elements. By the proper configuration of linear elastic springs (characterized by the stiffnesses $k_{1}$ and $k_{2}$ in Figure $3 \mathrm{~b}$ ), perfectly plastic body (characterized by the force $T_{0}$ in Figure $3 \mathrm{~b}$ ) and perfectly elastic body (characterized by the force $P_{0}$ in Figure $3 b)$ the hysteretic loop given in Figure $3 \mathrm{c}$ can be obtained. In such a configuration the perfectly plastic body is responsible for energy dissipation of the structure, while the perfectly elastic body, along with linear elastic springs, are responsible for energy accumulation. A detailed explanation as well as one-dimensional characteristics of elements are wider discussed in [26]. 
a)

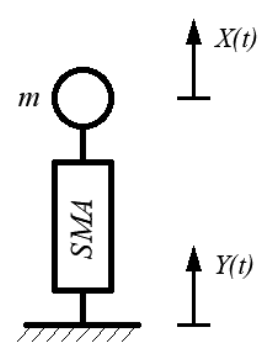

b)

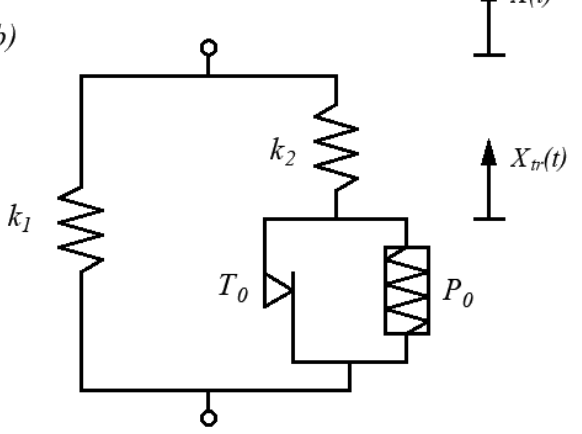

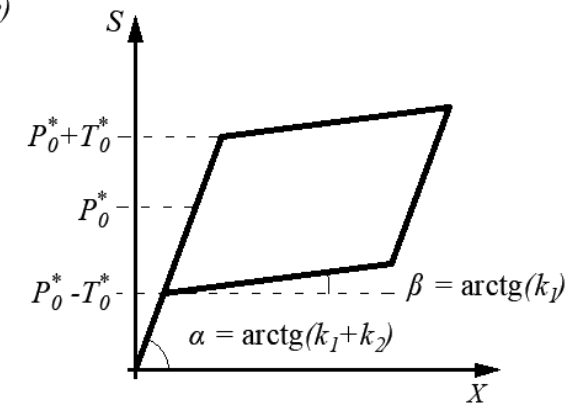

Figure 3: Schematic representation of SMA vibration control device, SMA rheological scheme and the graph of the hysteretic loop

The resultant hysteretic loop (Figure 3c) is characterized by the modified values of forces $P_{0}^{*}$ and $T_{0}^{*}$. The correction is a result of kinematic strengthening which is associated with the presence of the $k_{1}$ spring in the model. This implicates the increase of the initial value of the internal force at the beginning of the martensitic phase transformation. The correction is given by the equations

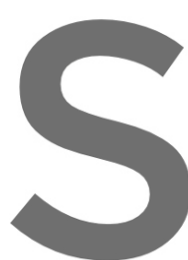

In the structural ana applied to the structure equations will be presen equation of motion of equation

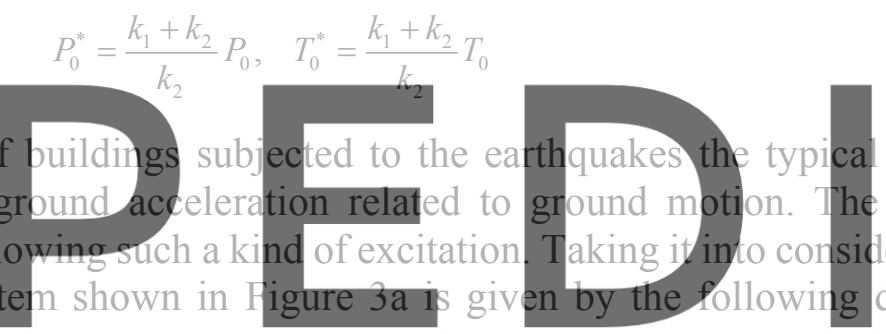
(1)

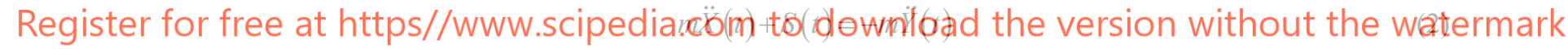
where $S(t)$ is a force response of SMA rheological model given by the equation

$$
\begin{aligned}
& S(t)=S_{1}(t)+S_{2}(t) \\
& S_{1}(t)=k_{1} X(t) \\
& S_{2}(t)=k_{2}\left(X(t)-X_{t r}(t)\right)
\end{aligned}
$$

The rate of deformation of the phase transformation $\dot{X}_{t r}$ is given by

$$
\dot{X}_{t r}=f_{S M A}\left(\dot{X}, X, X_{t r}\right)
$$

where

$$
f_{S M A}= \begin{cases}\dot{X} & \text { if } \quad\left|S_{2}\right|=P_{0}+T_{0} \text { and } S_{2} \dot{X}>0 \\ \dot{X} & \text { if }\left|S_{2}\right|=P_{0}-T_{0} \text { and } S_{2} \dot{X}<0 \text { and } S_{2} X_{t r}>0 \\ 0 & \text { otherwise }\end{cases}
$$

The above presented set of explicit non-linear differential equations enable to model a 
behaviour of SMAs in isothermal conditions in a certain temperature. In different temperatures values of $P_{0}$ and $T_{0}$ will vary. The generalization of the model for different thermal conditions is possible by determination of the relation between forces $P_{0}$ and $T_{0}$ and temperature. However this generalization does not influence the character of the presented equations.

\section{RESULTS COMPARISON}

In order to compare results of the discussed approach to constitutive modelling let consider a SDOF system presented earlier in Figure 3a. The damping of the mass displacements takes place due to stress induced phase transformation of SMA and its hysteretic response.

The considered excitation is a harmonic acceleration applied to the mass. Details of the excitation and material characteristics are given in Table 1. In order to make a comparison those values are based on the numerical example from the work of Lagoudas et al. [4].

Table 1 Design and material parameters
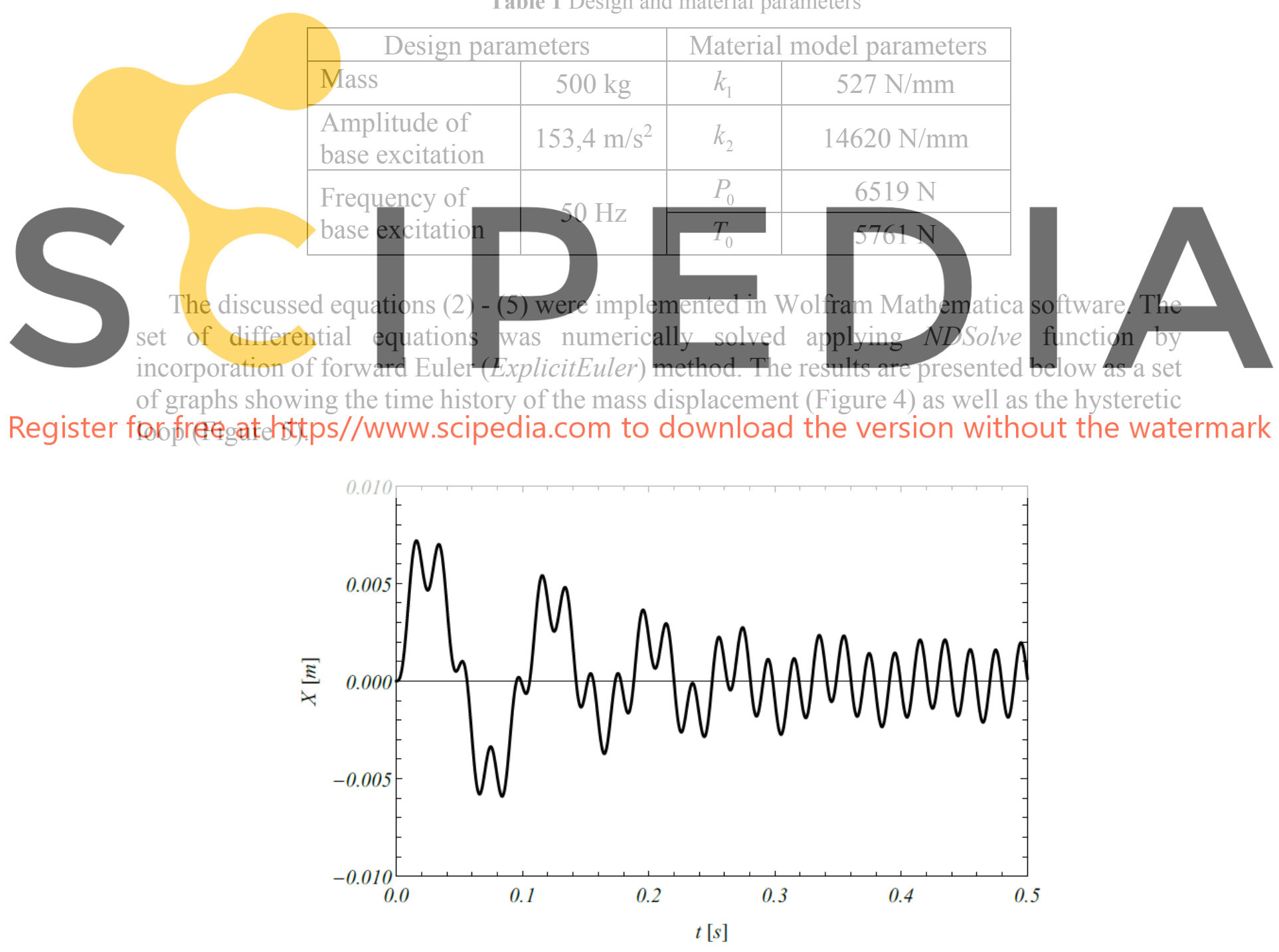

Figure 4 Time history of the mass displacement 


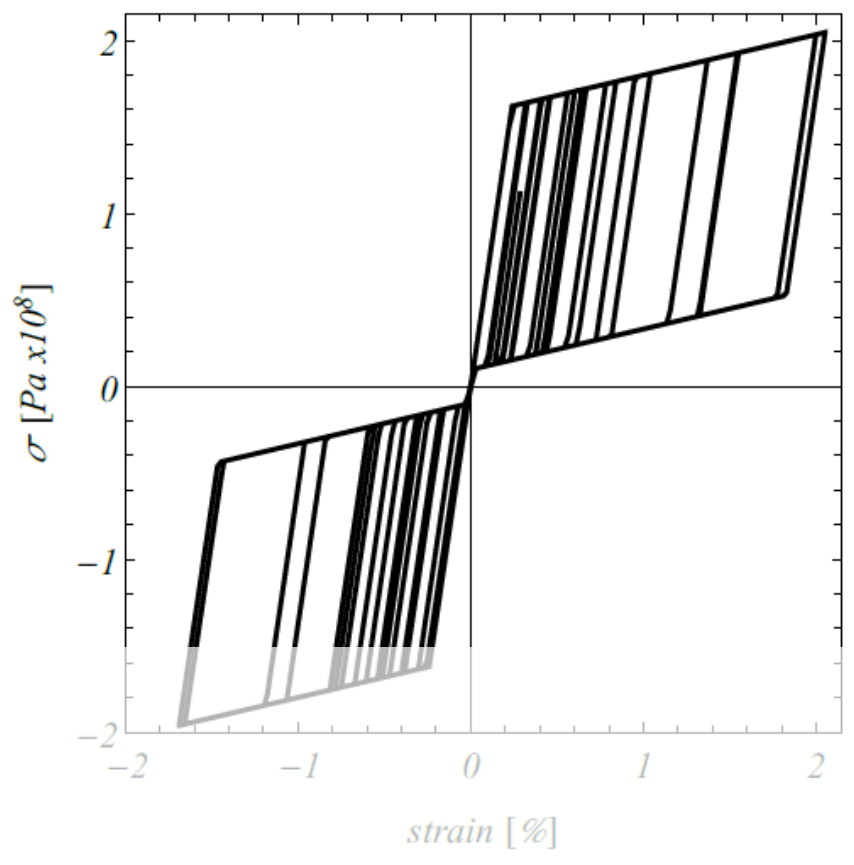

Figure 5 Hysteretic loop of the analyzed SMA device

The graph of the mass displacement history presents noticeable reduction of the amplitudes in the following cycles. The hysteretic loop behaviour of SMA.

Results obtained from basic polynomial m

Lagoudas et al. [4] ar dissimilarities of maximal and minimal valu graphs is coherent. This implicates that the presented formulation stays in agreement with

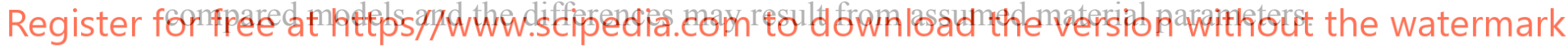

a)

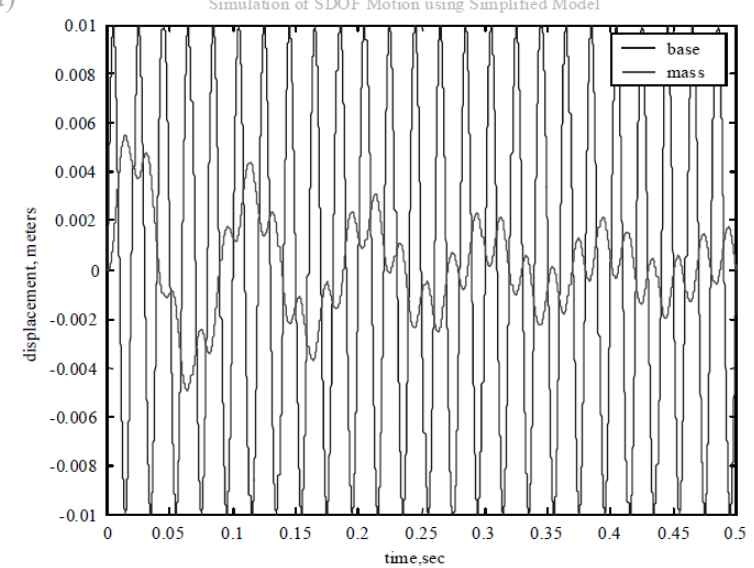

b)

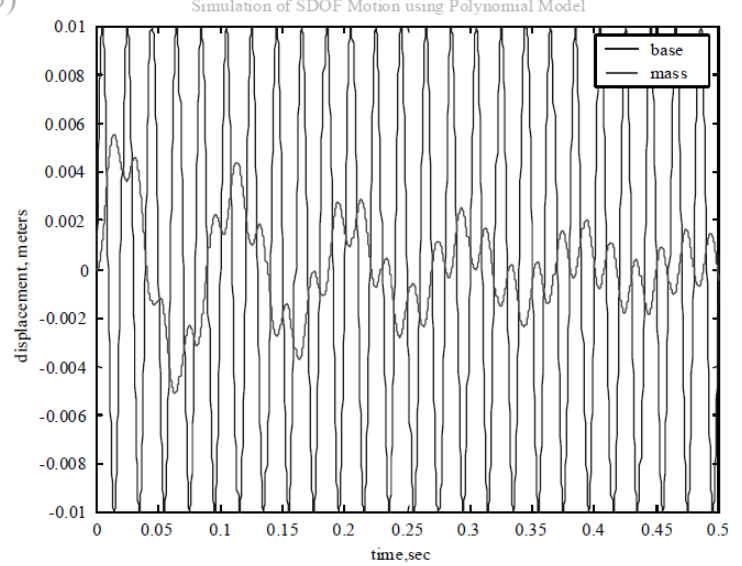

Figure 6 Maps of the displacements for different models of SMA [4] - a) simplified model and b) basic polynomial model 
a)

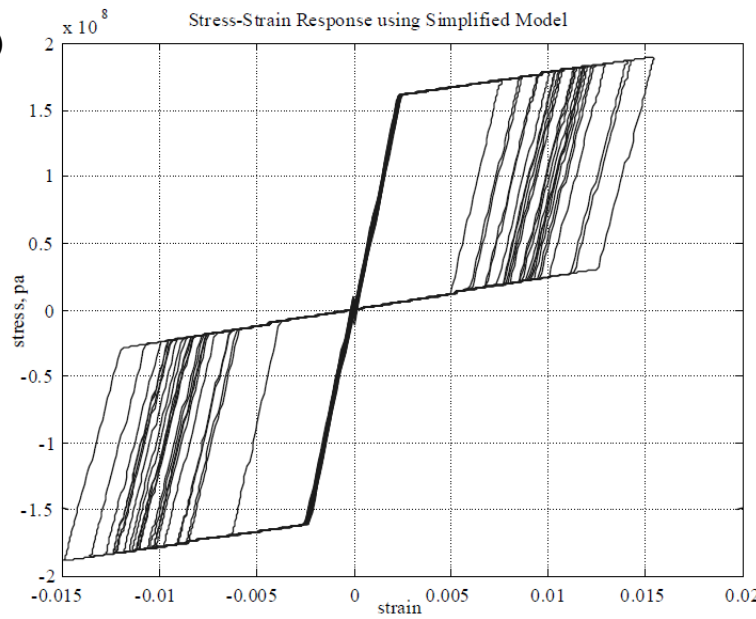

b)

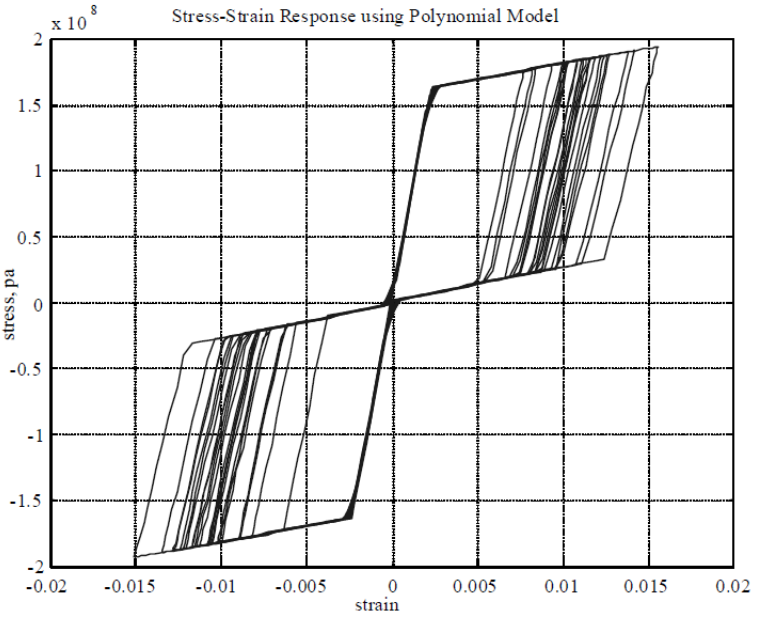

Figure 7 Hysteretic loops for different models of SMA [4] - a) simplified model and b) basic polynomial model

\section{CONCLUSIONS}

Results of the presented comparison of numerical example show the validity of the formulation. The important fact is that the proposed methodology of the formulation of SMA constitutive equations is based on original rheological schemes. It results in explicit form of differential equations implemented in mathen commercial FEM coder Abaqus [22-24]). Such such as historical mason
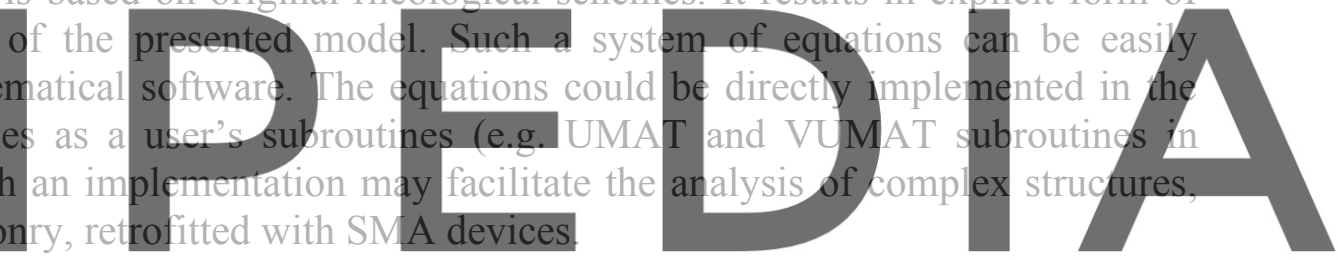

Register for free at KEtps//www.scipedia.com to download the version without the watermark

[1] Mohd Jani, J. Leary, M. Subic, A. and Gibson, M.A., A review of shape memory alloy research, applications and opportunities, Materials and Design (2014) 56: pp. 10781113.

[2] Lagoudas, D.C. Bo, Z. and Qidwai, M.A., A unified thermodynamic constitutive model for SMA and finite element analysis of active metal matrix composites, Mechanics of Composite Materials and Structures (1996) 3: pp. 153-179.

[3] Qidwai, M.A. and Lagoudas, D.C., Numerical implementation of a shape memory alloy thermomechanical constitutive model using return mapping algorithms, International Journal for Numerical Methods in Engineering (2000) 47: pp. 1123-1168.

[4] Lagoudas, D.C. Mayes, J.J. and Khan, M.M., Simplified shape memory alloy (SMA) material model for vibration isolation, in: Rao, V.S. (Ed.), International Society for Optics and Photonics, 2001: pp. 452-461.

[5] Ölander, A., An electrochemical investigation of solid cadmium-gold alloys, Journal of the American Chemical Society (1932) 54: pp. 3819-3833.

[6] Chang, L.C. and Read, T.A., Plastic Deformation and Diffusionless Phase Changes in Metals - the Gold-Cadmium Beta Phase, JOM (1951) 3: pp. 47-52.

[7] Buehler, W.J. Gilfrich, J. V. and Wiley, R.C., Effect of Low-Temperature Phase Changes 
on the Mechanical Properties of Alloys near Composition TiNi, Journal of Applied Physics (1963) 34: pp. 1475-1477.

[8] Asanović, V. and Delijić, K., The mechanical behavior and shape memory recovery of Cu-Zn-Al alloys, Metalurgija (2007) 13: pp. 59-64.

[9] Cladera, A. Weber, B. Leinenbach, C. Czaderski, C. Shahverdi, M. and Motavalli, M., Iron-based shape memory alloys for civil engineering structures: An overview, Construction and Building Materials (2014).

[10] Concilio, A. and Lecce, L., Historical Background and Future Perspectives, in: Shape Memory Alloy Engineering, Elsevier Ltd, 2015: pp. 3-30.

[11] Pecora, R. and Dimino, I., SMA for Aeronautics, Elsevier Ltd, 2014.

[12] Auricchio, F. Boatti, E. and Conti, M., SMA Biomedical Applications, Elsevier Ltd, 2014.

[13] Auricchio, F. Boatti, E. and Conti, M., SMA Cardiovascular Applications and ComputerBased Design, Elsevier Ltd, 2014

[14] Song, G. Ma, N. and Li, H.N., Applications of shape memory alloys in civil structures, Engineering Structures (2006) 28: pp. 1266-1274.

[15] Menna, C. Auricchio, F. and Asprone, D., Applications of Shape Memory Alloys in Structural Engineering, Elsevier Ltd, 2015.

[16] Castellano, M.G. Indirli, M. and Martelli, A., Progress of application, research and development, and design guidelines for shape memory alloy devices for cultural heritage

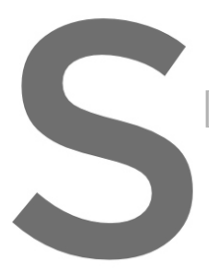
structures in Italy, in: Smart Structures and Materials 2001: Smart Systems for Bridges,
Structures, and Highways, 2001: po. 250-261.
Arato, G.B. Carpani, B. Forni, M. Indirli, M. Martelli, A. Castellano, M.G. and Medeot,
R., Application of innovative antseisnic techniques to the seismic retrofit of Italian
cultural heritage damaged by recent earthquakes, in: Monument-98, Workshop on
Seismic Performance of Monuments, 1998 . Indirli, M. Castellano, M.G. Clemente, P. and Martelli, A., Demo-application of shape

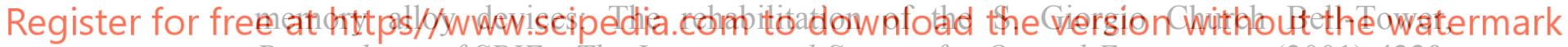
Proceedings of SPIE - The International Society for Optical Engineering (2001) 4330: pp. 262-272.

[19] Cardone, D. Angiuli, R. and Gesualdi, G., Application of Shape Memory Alloys in Historical Constructions, International Journal of Architectural Heritage (2019) 13: pp. 390-401.

[20] Ferretti, E. and Pascale, G., Some of the latest active strengthening techniques for Masonry Buildings: A critical analysis, Materials (2019) 12:.

[21] Cisse, C. Zaki, W. and Ben Zineb, T., A review of constitutive models and modeling techniques for shape memory alloys, International Journal of Plasticity (2016) 76: pp. 244-284.

[22] Grzesikiewicz, W. and Zbiciak, A., Constitutive modelling of pseudoelastic material using Kepes-type rheological element, Computer Systems Aided Science and Engineering Work in Transport, Mechanics and Electrical Engineering (2008) 122: pp. 159-164.

[23] Zbiciak, A., Dynamic analysis of pseudoelastic SMA beam, International Journal of Mechanical Sciences (2010) 52: pp. 56-64.

[24] Grzesikiewicz, W. Wakulicz, A. and Zbiciak, A., Mathematical modelling of rate- 
independent pseudoelastic SMA material, International Journal of Non-Linear Mechanics (2011) 46: pp. 870-876.

[25] Zbiciak, A. and Wasilewski, K., Constitutive Modelling and Numerical Implementation of SMA Material with Internal Loops, Archives of Civil Engineering (2018) 64: pp. 211 232.

[26] Zbiciak, A. and Wasilewski, K., Modelling of single degree of freedom SMA oscillators by using rheological schemes, in: MATEC Web of Conferences, 2018.
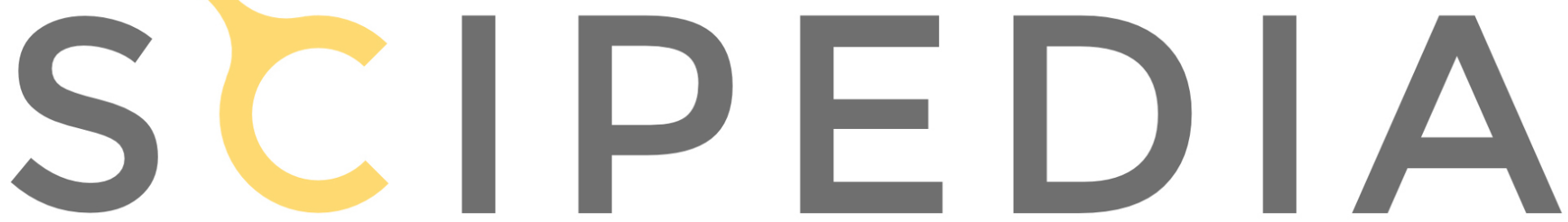

Register for free at https//www.scipedia.com to download the version without the watermark 